\title{
Association of serum 25-hydroxyvitamin D with insulin resistance and $\beta$-cell function in a healthy Chinese female population
}

\author{
Min-fang TAO ${ }^{1, \#}$, Zeng ZHANG ${ }^{2,3, \#}$, Yao-hua KE ${ }^{2}$, Jin-wei $\mathrm{HE}^{2}$, Wen-zhen $\mathrm{FU}^{2}$, Chang-qing ZHANG ${ }^{3}$, Zhen-lin ZHANG ${ }^{2, *}$ \\ ${ }^{1}$ Department of Gynecology and Obstetrics, Shanghai Jiao Tong University Affiliated Sixth People's Hospital, Shanghai 200233, China; \\ ${ }^{2}$ Metabolic Bone Disease and Genetic Research Unit, Department of Osteoporosis and Bone Diseases, Shanghai Jiao Tong University \\ Affiliated Sixth People's Hospital, Shanghai 200233, China; ${ }^{3}$ Department of Orthopedic Surgery, Shanghai Jiao Tong University Affili- \\ ated Sixth People's Hospital, Shanghai 200233, China
}

Aim: To assess associations of the serum level of 25-hydroxyvitamin D with insulin resistance and $\beta$-cell function in a healthy Chinese female population.

Methods: This cross-sectional study included 1382 female participants free of type 2 diabetes who were recruited in Shanghai. Blood samples were collected within a winter season and the serum levels of 25-hydroxyvitamin D, fasting plasma glucose and insulin, and other biochemical parameters were determined. Insulin resistance and $\beta$-cell function were assessed using the homeostasis model assessments of insulin resistance (HOMA-IR) and $\beta$-cell function (HOMA-B), respectively.

Results: Multiple linear regression analyses adjusted for age, parathyroid hormone, $\mathrm{Ca}^{2+}$ and $\mathrm{BMI}$ revealed that independent inverse associations existed between the serum level of 25-hydroxyvitamin D and HOMA-IR $(P<0.001)$ and between the serum level of 25-hydroxyvitamin D and HOMA-B ( $P=0.001)$.

Conclusion: Serum vitamin D level is significantly and independently associated with insulin resistance and $\beta$-cell function in a healthy Chinese female population.

Keywords: vitamin D; 25-hydroxyvitamin D; type 2 diabetes; $\beta$-cell function; insulin resistance; female

Acta Pharmacologica Sinica (2013) 34: 1070-1074; doi: 10.1038/aps.2013.13; published online 17 Jun 2013

\section{Introduction}

Type 2 diabetes is one of the most common endocrine diseases worldwide, currently affecting more than 300 million people. Over time, type 2 diabetes leads to an increased risk of severe complications such as coronary heart disease, stroke, blindness, kidney failure, and nerve damage. The rates of type 2 diabetes are still increasing, mainly driven by increasing levels of obesity ${ }^{[1]}$. Given that reversing the rising obesity levels is unlikely, identification of easily modifiable risk factors is urgently needed for the primary prevention of type 2 diabetes.

One of these easily modifiable risk factors-vitamin D statushas received considerable attention. Emerging evidence suggests a role for vitamin $\mathrm{D}$ in the etiology of type 2 diabetes ${ }^{[2,3]}$. Because insulin resistance is a risk factor for diabetes, under-

\footnotetext{
\#These authors contributed equally to this work.

* To whom correspondence should be addressed.

E-mail zz12002@medmail.com.cn

Received 2012-11-10 Accepted 2013-02-19
}

standing the role of vitamin $\mathrm{D}$ in the pathogenesis of diabetes and impaired glucose tolerance is important in the effort to combat the increasing prevalence of diabetes worldwide.

Vitamin D is hypothesized to play a role in glucose homeostasis and $\beta$-cell function ${ }^{[4]}$. In adults, low 25-hydroxyvitamin $[25(\mathrm{OH}) \mathrm{D}]$ concentration have been found to be associated with higher risk of hyperglycemia, insulin resistance, and type 2 diabetes ${ }^{[5]}$. In children, limited vitamin D data show an association with fasting hyperglycemia and insulin resistance ${ }^{[6,7]}$. Animal data show impaired insulin secretion during vitamin D deficiency ${ }^{[8]}$ and an improvement in insulin secretion with vitamin $\mathrm{D}$ supplementation $^{[9,10]}$. This impairment is primarily caused by the direct effect of vitamin D deficiency on the $\beta$-cell ${ }^{[11]}$. Vitamin D receptors have been identified on pancreatic $\beta$-cells ${ }^{[12]}$, and the active metabolite of vitamin $D, 1,25$ dihydroxyvitamin $D$, is thought to be required for normal glucose-stimulated insulin release from $\beta$-cells ${ }^{[13]}$.

However, large-scale population-based studies examining the correlation between vitamin D insufficiency and 
type 2 diabetes show heterogeneous results depending on ethnicity ${ }^{[2,4,14,15]}$. Recently, Lu et al ${ }^{[16]}$ evaluated the association between $25(\mathrm{OH}) \mathrm{D}$ and metabolic syndrome among middleaged and elderly Chinese individuals and suggested that a low $25(\mathrm{OH}) \mathrm{D}$ level was significantly associated with an increased risk of having metabolic syndrome and insulin resistance (IR). However, there still is a lack of studies on the association of vitamin $\mathrm{D}$ with IR and $\beta$-cell dysfunction in healthy adult Chinese individuals. Therefore, our objective was to assess the association between the serum 25(OH)D concentration and both IR and $\beta$-cell dysfunction in a large cohort of healthy adult Chinese females.

\section{Materials and methods Study population}

From February 2009 to March 2009, a total of 1400 healthy Chinese females (aged 20-85 years) living in Shanghai were recruited from several community centers. The participants were identical to those included in the Shanghai Osteoporosis Study. This study assessed the physical health of the participants, including heart, liver, kidney, and bone health. The study subjects were recruited from ten urban communities in Shanghai. After stratifying the population of each selected community by age, we sampled subjects. All of the subjects who agreed to participate in this study were asked to visit an outpatient clinic at the Department of Osteoporosis and Bone Diseases, Shanghai Jiao Tong University Affiliated Sixth People's Hospital. The response rate for participation was $85.6 \%$. All of the participants were of Han ethnicity. Age, body weight, height, and age at menarche and amenorrhea were recorded.

All of the subjects were subjected to blood counts, fasting plasma glucose tests, and liver and kidney function tests. All of the healthy subjects included in this study had (1) normal blood counts and (2) normal results for liver and kidney function. Subjects with fasting plasma glucose levels $>7.0 \mathrm{mmol} / \mathrm{L}$ $(n=12)$ were excluded. Information on smoking and alcohol drinking habits was collected by questionnaire. Several $(n=6)$ of the subjects were smokers and/or drinkers, so they were excluded. Participants who were on diabetes medication or had a history of diabetes, or had taken vitamin D and/or calcium supplements within 3 months were also excluded.

The study was approved by the Ethics Committee of the Shanghai Jiao Tong University Affiliated Sixth People's Hospital. All of the participants signed informed consent forms before entering the study.

\section{Blood collection and analysis}

Fasting blood samples were collected for the measurement of the serum levels of calcium, phosphate, albumin, glucose, insulin, intact parathyroid hormone (iPTH) and 25-hydroxyvitamin D [25(OH)D]. Serum levels of 25(OH)D and PTH were determined using an ECLIA Elecsys autoanalyzer (Roche Diagnostic $\mathrm{GmbH}$, Mannheim, Germany). The intra-assay and inter-assay coefficients of variation $(\mathrm{CVs})$ for $25(\mathrm{OH}) \mathrm{D}$ were $5.6 \%$ and $8.0 \%$, respectively. The lower limit of detection of $25(\mathrm{OH}) \mathrm{D}$ was $<4 \mathrm{ng} / \mathrm{mL}(10 \mathrm{mmol} / \mathrm{L})$. The intra-assay and inter-assay CVs for PTH were $1.4 \%$ and $2.9 \%$, respectively. The intra-assay and inter-assay CVs for fasting plasma glucose were $1.9 \%$ and $2.6 \%$, respectively. The intra-assay and inter-assay CVs for fasting plasma insulin were $1.4 \%$ and $2.9 \%$, respectively. Insulin resistance and $\beta$-cell function were estimated based on the fasting plasma measurements using the HOMA-IR [fasting plasma insulin $(\mathrm{mU} / \mathrm{L}) \times$ fasting glucose $(\mathrm{mmol} / \mathrm{L}) \div 22.5]$ and HOMA-B [20×fasting plasma insulin $(\mathrm{mU} / \mathrm{L}) \div($ fasting glucose $(\mathrm{mmol} / \mathrm{L})-3.5)]$, respectively ${ }^{[17]}$. All of the serum samples were obtained during the winter season (February 2009 to March 2009).

\section{Statistical analysis}

Continuous variables are presented as mean $( \pm S D)$. Data that are not normally distributed are shown as medians and interquartile ranges (in parentheses). The data that were not normally distributed were log transformed before analysis. Differences in the levels of $25(\mathrm{OH})$ between subjects before and after menopause were tested by Student's $t$-test. We tested differences using linear trends for continuous traits across $25(\mathrm{OH}) \mathrm{D}$ categories using generalized linear models. Simple linear analysis was used to assess the relationship between the serum $25(\mathrm{OH}) \mathrm{D}$ concentration and various parameters. Multiple linear regression analyses were conducted to investigate the independent associations of $25(\mathrm{OH}) \mathrm{D}$ with measures of insulin resistance (HOMA-IR) and $\beta$-cell dysfunction (HOMA-B). Age and BMI have been previously associated with type 2 diabetes. PTH and Ca may be the mediators of the insulin resistance. Therefore, they were chosen as confounding factors. Three models were constructed. Model 1 was adjusted for age, model 2 was additionally adjusted for PTH and $\mathrm{Ca}$, and model 3 was additionally adjusted for BMI. All of the calculations were performed using SPSS ver 11.0 (SPSS Inc, Chicago, IL, USA). The results were considered to be statistically significant at $P<0.05$.

\section{Results}

The clinical characteristics and mean laboratory values of the 1382 women, aged 20-85 years, are shown in Table 1 across tertiles of $25(\mathrm{OH}) \mathrm{D}$ concentration. The study cohort had a mean $( \pm S D)$ age of $37.3 \pm 12.6$ years, a mean $( \pm S D)$ BMI of $21.9 \pm 2.8$ and a mean $( \pm S D)$ serum $25(\mathrm{OH}) \mathrm{D}$ concentration of $20.7 \pm 6.7 \mathrm{ng} / \mathrm{mL}$. The proportion of overweight participants $(\mathrm{BMI}>23)$ based on Asian criteria ${ }^{[18]}$ was $29.2 \%$. Differences in the $25(\mathrm{OH}) \mathrm{D}$ level were significantly associated with fasting serum insulin, HOMA-IR and HOMA-B but not fasting serum glucose. In addition, the subjects before menopause (20.4 \pm 5.8$)$ had a slightly higher mean level of $25(\mathrm{OH}) \mathrm{D}$ than those after menopause (19.9 \pm 6.3$)$, but the difference was not significant.

Bivariate correlations between the $25(\mathrm{OH}) \mathrm{D}$ concentration and various parameters are shown in Table 2. The $25(\mathrm{OH}) \mathrm{D}$ concentration was inversely associated with PTH, fasting insulin, HOMA-IR and HOMA-B but not with age, BMI, or fasting glucose.

In the multivariate regression analysis, the serum $25(\mathrm{OH}) \mathrm{D}$ 
Table 1. Participant characteristics.

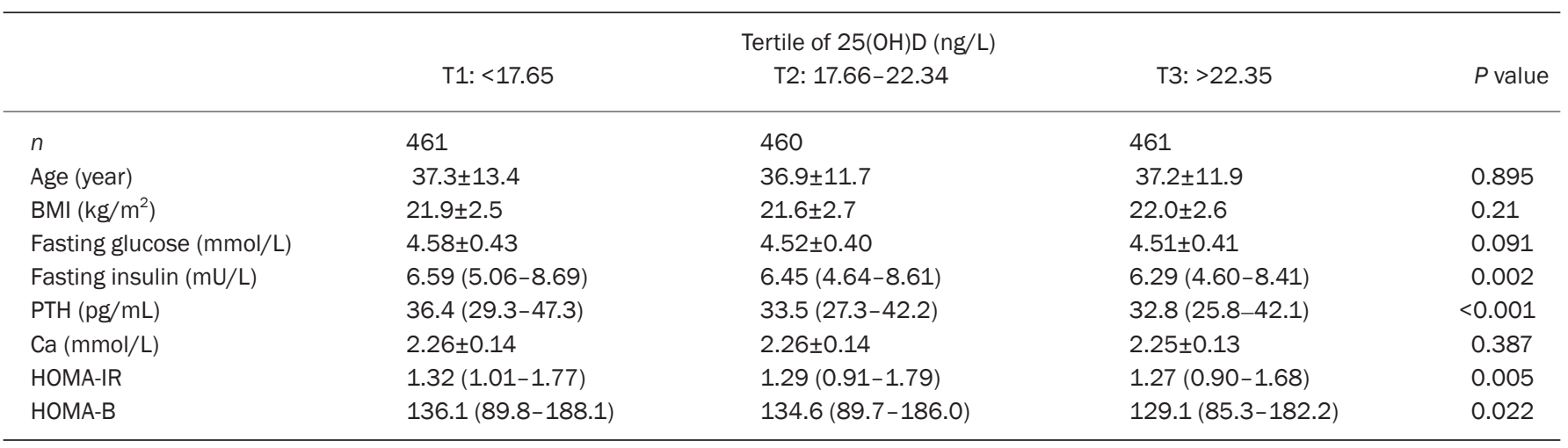

Continuous variables are presented as mean \pm SD. Data that are not normally distributed are shown as medians and inter-quartile ranges (in parentheses). $P$ values are the test for linear trend for continuous traits.

Table 2. Correlation coefficients between the serum 25(OH)D concentration and various parameters.

\begin{tabular}{lrr}
\hline & $r$ & \multicolumn{1}{c}{$P$} \\
\hline Age & 0.003 & 0.914 \\
BMI & 0.035 & 0.212 \\
PTH & -0.164 & $<0.001$ \\
Ca & -0.052 & 0.072 \\
Fasting glucose & -0.062 & 0.075 \\
Fasting insulin & -0.093 & 0.001 \\
HOMA-IR & -0.103 & $<0.001$ \\
HOMA-B & -0.092 & 0.001 \\
\hline
\end{tabular}

concentration was a significant independent predictor of insulin resistance and $\beta$-cell function across all models (Table 3 ).

\section{Discussion}

The major finding of this study is that the serum level of $25(\mathrm{OH}) \mathrm{D}$ was inversely associated with insulin resistance and $\beta$-cell function. These relationships were independent of confounding factors. Therefore, an abnormal vitamin D status may be a risk factor for type 2 diabetes.

Previous studies assessing the association between vitamin D and insulin resistance, as well as vitamin D and $\beta$-cell function, have yielded inconsistent results. On the one hand, epidemiologic studies ${ }^{[2,4,15,19]}$ have suggested that the serum $25(\mathrm{OH}) \mathrm{D}$ concentration or the VDR polymorphism is associ- ated with insulin sensitivity. Stronger evidence comes from prospective studies, of which there have been two that show inverse associations between dietary vitamin $\mathrm{D}$ and diabetes $\operatorname{risk}^{[20,21]}$. Furthermore, a recent meta-analysis of two representative Finnish cohorts showed a satisfactory vitamin D level also plays an important role in primary diabetes prevention ${ }^{[22]}$. On the other hand, Gulseth et al ${ }^{[14]}$ showed that serum concentrations of $25(\mathrm{OH}) \mathrm{D}$ did not predict insulin action or secretion in a sample of subjects with metabolic syndrome. Moreover, no effect of 1alpha, 25-dihydroxyvitamin $\mathrm{D}_{3}$ on beta-cell residual function and insulin requirement in adults with new-onset type 1 diabetes was observed ${ }^{[23]}$. These inconsistent results may result from small sample sizes, the use of indirect measures of insulin resistance and $\beta$-cell function, and/or different study populations (ie, ethnicity, healthy subjects or subjects with metabolic syndrome). Our study found that the serum level of $25(\mathrm{OH}) \mathrm{D}$ was inversely associated with insulin resistance and $\beta$-cell function in a large sample of healthy adult Chinese females, independent of confounding factors.

The relationships between $25(\mathrm{OH}) \mathrm{D}$ and parameters of glucose homeostasis are often confounded by other factors such as adiposity and PTH. Obesity is clearly the predominant factor in the pathogenesis of diabetes. It is known to be associated with reduced vitamin D status, which may reflect some of the lifestyle factors such as the levels of exercise, alcohol consumption, and smoking, or the increased sequestration of vitamin $\mathrm{D}$ in adipose tissue ${ }^{[24]}$. A recent study aiming to explore the effect of modification of obesity on the association between $25(\mathrm{OH}) \mathrm{D}$ and insulin resistance showed that within

Table 3. Multiple linear regression analysis of the association between serum 25(OH)D concentration and both HOMA-IR and HOMA-B.

\begin{tabular}{|c|c|c|c|c|c|c|}
\hline & \multicolumn{2}{|l|}{ Model 1} & \multicolumn{2}{|l|}{ Model 2} & \multicolumn{2}{|l|}{ Model 3} \\
\hline & $\beta(95 \% \mathrm{Cl})$ & $P$ & $\beta(95 \% \mathrm{Cl})$ & $P$ & $\beta(95 \% \mathrm{Cl})$ & $P$ \\
\hline HOMA-IR & $-0.004(-0.006$ to -0.002$)$ & 0.001 & $-0.006(-0.006$ to -0.001$)$ & 0.001 & $-0.004(-0.007$ to -0.002$)$ & $<0.001$ \\
\hline HOMA-B & $-0.009(-0.014$ to -0.003$)$ & $<0.001$ & $-0.011(-0.015$ to -0.004$)$ & $<0.001$ & $-0.010(-0.017$ to -0.004$)$ & 0.001 \\
\hline
\end{tabular}

Model 1, adjusted for age; model 2, additionally adjusted for PTH and Ca; and model 3, additionally adjusted for BMI. 
a cross-sectional, nationally representative sample, abdominal obesity and insufficient 25(OH)D interact to synergistically influence the risk of insulin resistance ${ }^{[25]}$. However, one feature of this sample is the relatively low average BMI (21.9 \pm 2.8$)$, which reflects a major difference between East Asian women and women from Western countries. The proportion of overweight participants (BMI>23) based on Asian criteria ${ }^{[18]}$ in this study was $29.2 \%$. The low average BMI and the low proportion of overweight participants are comparable to other studies in Shanghai ${ }^{[26]}$, and are representative of the general urban female population of Shanghai. Since previous studies ${ }^{[27-30]}$ mainly focused on the relationship between vitamin D insufficiency and insulin resistance in obese populations, the results of our study provide evidence that abnormal vitamin D status may play a role in the pathogenesis of diabetes in a population with relatively low BMI.

Another common confounding factor is PTH. Previous studies have shown that secondary hyperparathyroidism may be the chief mediator of the insulin resistance associated with poor vitamin D status and/or other variables ${ }^{[31]}$. PTH can increase free intracellular calcium concentrations in key insulin target tissues, including adipocytes and skeletal muscle ${ }^{[32,33]}$. Previous studies observed that increased PTH concentrations were associated with impaired glucose tolerance and decreased insulin sensitivity ${ }^{[34,35]}$. Yamaguchi et al ${ }^{[36]}$ showed that serum Ca level was positively associated with impaired glucose metabolism, independently of PTH and bone metabolism, in men with type 2 diabetes. Our data showed that the serum $25(\mathrm{OH}) \mathrm{D}$ concentration was inversely and significantly associated with HOMA-IR in both sexes after adjustment for serum intact PTH and Ca levels and suggest that vitamin D has a role in the pathogenesis of impaired glucose metabolism independent of PTH and Ca.

The possible mechanisms underlying the relationship between vitamin $\mathrm{D}$ and glucose homeostasis include direct effects of vitamin $D$ on pancreatic $\beta$-cell secretory function (through nuclear VDRs), effects on insulin sensitivity (through stimulation of insulin receptor expression regulation of intracellular calcium since an effector part of the vitamin D pathway is the vitamin D-dependent calcium-binding protein required for postinsulin receptor effects in insulin-responsive tissues, and indirect effects (through inflammatory processes) ${ }^{[2,37,38]}$. In addition, 25(OH)D deficiency leads to hyperparathyroidism, which in turn has been found to be inversely associated with insulin sensitivity in healthy adults ${ }^{[34]}$.

The strengths of the current study include the large, wellcharacterized sample of subjects free of type 2 diabetes. In addition, the 25(OH)D level and other biochemical parameters were measured in blood samples obtained during the winter season to avoid a seasonal effect. Some limitations should be noted. Lifestyles, such as frequent outdoor exercise, could influence both the vitamin D status and insulin sensitivity and thus might account for the observed correlation. Other limitations include the cross-sectional design and the lack of 'gold standard' measures of IR, which are invasive and costly and thus not suited for use in large studies.
In conclusion, the vitamin D level was significantly and independently associated with IR and $\beta$-cell function in a large cohort of healthy Chinese females free of type 2 diabetes. These associations are potentially important for understanding the etiology of abnormal glucose metabolism. Further study is needed on the proposed association between vitamin $\mathrm{D}$ and the disorders underlying type 2 diabetes in large populationbased studies.

\section{Acknowledgements}

This study was supported by the National Natural Science Foundation of China (81070692, 81000360, and 81170803), the Program of the Shanghai Subject Chief Scientist (08XD1403000) and Science and Technology Commission of Shanghai Municipality (10DZ1950100), Academic Leaders in Health Sciences in Shanghai (XBR2011014) and Shanghai Leading Talent Plan (051).

\section{Author contribution}

Zhen-lin ZHANG and Chang-qing ZHANG designed research; Jin-wei HE, Yao-hua KE, and Wen-zhen FU performed research; Zeng ZHANG analyzed data; and Min-fang TAO and Zeng ZHANG wrote the paper.

\section{References}

1 Wild S, Roglic G, Green A, Sicree R, King H. Global prevalence of diabetes: estimates for the year 2000 and projections for 2030. Diabetes Care 2004; 27: 1047-53.

2 Forouhi NG, Luan J, Cooper A, Boucher BJ, Wareham NJ. Baseline serum 25-hydroxy vitamin $D$ is predictive of future glycemic status and insulin resistance: the Medical Research Council Ely Prospective Study 1990-2000. Diabetes 2008; 57: 2619-25.

3 Mattila C, Knekt P, Mannisto S, Rissanen H, Laaksonen MA, Montonen J, et al. Serum 25-hydroxyvitamin D concentration and subsequent risk of type 2 diabetes. Diabetes Care 2007; 30: 2569-70.

4 Chiu KC, Chu A, Go VL, Saad MF. Hypovitaminosis D is associated with insulin resistance and beta cell dysfunction. Am J Clin Nutr 2004; 79: 820-5.

5 Kayaniyil S, Vieth R, Retnakaran R, Knight JA, Qi Y, Gerstein HC, et al. Association of vitamin $\mathrm{D}$ with insulin resistance and beta-cell dysfunction in subjects at risk for type 2 diabetes. Diabetes Care 2010; 33: 1379-81.

6 Pacifico L, Anania C, Osborn JF, Ferraro F, Bonci E, Olivero E, et al. Low $25(\mathrm{OH}) \mathrm{D}_{3}$ levels are associated with total adiposity, metabolic syndrome, and hypertension in Caucasian children and adolescents. Eur J Endocrinol 2011; 165: 603-11.

7 Nsiah-Kumi PA, Erickson JM, Beals JL, Ogle EA, Whiting M, Brushbreaker $\mathrm{C}$, et al. Vitamin d insufficiency is associated with diabetes risk in Native American children. Clin Pediatr (Phila) 2012; 51: 146-53.

8 Norman AW, Frankel JB, Heldt AM, Grodsky GM. Vitamin D deficiency inhibits pancreatic secretion of insulin. Science 1980; 209: 823-5.

9 Ayesha I, Bala TS, Reddy CV, Raghuramulu N. Vitamin D deficiency reduces insulin secretion and turnover in rats. Diabetes Nutr Metab 2001; 14: 78-84.

10 Kadowaki S, Norman AW. Dietary vitamin D is essential for normal insulin secretion from the perfused rat pancreas. J Clin Invest 1984; 73: 759-66.

11 Mathieu C, Gysemans C, Giulietti A, Bouillon R. Vitamin D and 
diabetes. Diabetologia 2005; 48: 1247-57.

12 Johnson JA, Grande JP, Roche PC, Kumar R. Immunohistochemical localization of the $1,25(\mathrm{OH})_{2} \mathrm{D}_{3}$ receptor and calbindin $\mathrm{D} 28 \mathrm{~K}$ in human and rat pancreas. Am J Physiol 1994; 267: E356-60.

13 Maestro B, Campion J, Davila N, Calle C. Stimulation by 1,25-dihydroxyvitamin $D_{3}$ of insulin receptor expression and insulin responsiveness for glucose transport in U-937 human promonocytic cells. Endocr J 2000; 47: 383-91.

14 Gulseth HL, Gjelstad IM, Tierney AC, Lovegrove JA, Defoort C, Blaak $\mathrm{EE}$, et al. Serum vitamin $\mathrm{D}$ concentration does not predict insulin action or secretion in European subjects with the metabolic syndrome. Diabetes Care 2010; 33: 923-5.

15 Rhee SY, Hwang YC, Chung HY, Woo JT. Vitamin D and diabetes in Koreans: analyses based on the Fourth Korea National Health and Nutrition Examination Survey (KNHANES), 2008-2009. Diabet Med 2012; 29: 1003-10.

16 Lu L, Yu Z, Pan A, Hu FB, Franco OH, Li H, et al. Plasma 25-hydroxyvitamin $D$ concentration and metabolic syndrome among middle-aged and elderly Chinese individuals. Diabetes Care 2009; 32: 1278-83.

17 Matthews DR, Hosker JP, Rudenski AS, Naylor BA, Treacher DF, Turner RC. Homeostasis model assessment: insulin resistance and beta-cell function from fasting plasma glucose and insulin concentrations in man. Diabetologia 1985; 28: 412-9.

18 WHO Expert Consultation. Appropriate body-mass index for Asian populations and its implications for policy and intervention strategies. Lancet 2004; 363: 157-63.

19 Oh JY, Barrett-Connor E. Association between vitamin D receptor polymorphism and type 2 diabetes or metabolic syndrome in communitydwelling older adults: the Rancho Bernardo Study. Metabolism 2002; 51: 356-9.

20 Liu S, Song Y, Ford ES, Manson JE, Buring JE, Ridker PM. Dietary calcium, vitamin $D$, and the prevalence of metabolic syndrome in middle-aged and older US women. Diabetes Care 2005; 28: 292632.

21 Pittas AG, Dawson-Hughes B, Li T, Van Dam RM, Willett WC, Manson $\mathrm{JE}$, et al. Vitamin $\mathrm{D}$ and calcium intake in relation to type 2 diabetes in women. Diabetes Care 2006; 29: 650-6.

22 Laaksonen MA, Knekt P, Rissanen H, Harkanen T, Virtala E, Marniemi J, et al. The relative importance of modifiable potential risk factors of type 2 diabetes: a meta-analysis of two cohorts. Eur J Epidemiol 2010; 25: 115-24.

23 Walter M, Kaupper T, Adler K, Foersch J, Bonifacio E, Ziegler AG. No effect of the 1alpha,25-dihydroxyvitamin D3 on beta-cell residual function and insulin requirement in adults with new-onset type 1 diabetes. Diabetes Care 2010; 33: 1443-8.

24 Blum M, Dolnikowski G, Seyoum E, Harris SS, Booth SL, Peterson J, et al. Vitamin $D_{3}$ in fat tissue. Endocrine 2008; 33: 90-4.

25 Kabadi SM, Lee BK, Liu L. Joint effects of obesity and vitamin D insufficiency on insulin resistance and type 2 diabetes: results from the NHANES 2001-2006. Diabetes Care 2012; 35: 2048-54

26 Hou X, Jia W, Bao Y, Lu H, Jiang S, Zuo Y, et al. Risk factors for overweight and obesity, and changes in body mass index of Chinese adults in Shanghai. BMC Public Health 2008; 8: 389.

27 Buyukinan M, Ozen S, Kokkun S, Saz EU. The relation of vitamin D deficiency with puberty and insulin resistance in obese children and adolescents. J Pediatr Endocrinol Metab 2012; 25: 83-7.

28 Harris SS, Pittas AG, Palermo NJ. A randomized, placebo-controlled trial of vitamin $D$ supplementation to improve glycaemia in overweight and obese African Americans. Diabetes Obes Metab 2012; 14: 78994.

29 Poomthavorn P, Saowan S, Mahachoklertwattana P, Chailurkit L, Khlairit P. Vitamin D status and glucose homeostasis in obese children and adolescents living in the tropics. Int J Obes (Lond) 2012; 36: 491-5.

30 Olson ML, Maalouf NM, Oden JD, White PC, Hutchison MR. Vitamin $D$ deficiency in obese children and its relationship to glucose homeostasis. J Clin Endocrinol Metab 2012; 97: 279-85.

31 Roislien J, Van Calster B, Hjelmesaeth J. Parathyroid hormone is a plausible mediator for the metabolic syndrome in the morbidly obese: a cross-sectional study. Cardiovasc Diabetol 2011; 10: 17.

32 Fuleihan GE, Deeb M. Hypovitaminosis D in a sunny country. N Engl J Med 1999; 340: 1840-1.

33 Arunabh S, Pollack S, Yeh J, Aloia JF. Body fat content and 25hydroxyvitamin $D$ levels in healthy women. J Clin Endocrinol Metab 2003; 88: 157-61.

34 Chiu KC, Chuang LM, Lee NP, Ryu JM, McGullam JL, Tsai GP, et al. Insulin sensitivity is inversely correlated with plasma intact parathyroid hormone level. Metabolism 2000; 49: 1501-5.

35 Reis JP, von Muhlen D, Kritz-Silverstein D, Wingard DL, BarrettConnor E. Vitamin D, parathyroid hormone levels, and the prevalence of metabolic syndrome in community-dwelling older adults. Diabetes Care 2007; 30: 1549-55.

36 Yamaguchi T, Kanazawa I, Takaoka S, Sugimoto T. Serum calcium is positively correlated with fasting plasma glucose and insulin resistance, independent of parathyroid hormone, in male patients with type 2 diabetes mellitus. Metabolism 2011; 60: 1334-9.

37 Tai K, Need AG, Horowitz M, Chapman IM. Vitamin D, glucose, insulin, and insulin sensitivity. Nutrition 2008; 24: 279-85.

38 Timms PM, Mannan N, Hitman GA, Noonan K, Mills PG, SyndercombeCourt D, et al. Circulating MMP9, vitamin D and variation in the TIMP-1 response with VDR genotype: mechanisms for inflammatory damage in chronic disorders? QJM 2002; 95: 787-96. 